\title{
Nucleation Effect of the Chemical Structure of Alkylammonium Salt on the Crystallization Behavior of Poly(Vinylidene Fluoride)
}

\author{
Tatsuaki Miyashita $\mathbb{D}^{1,2}$ and Hiromu Saito $\mathbb{D}^{2}$ \\ ${ }^{1}$ KF Products Department, Kureha Corporation, 3-3-2 Nihonbashi-Hamacho, Chuo-ku, Tokyo 103-8552, Japan \\ ${ }^{2}$ Department of Organic and Polymer Materials Chemistry, Tokyo University of Agriculture and Technology, \\ 2-24-16 Naka-machi, Koganei-shi, Tokyo 184-8588, Japan \\ Correspondence should be addressed to Tatsuaki Miyashita; tatsuaki-miyashita@kureha.co.jp
}

Received 14 December 2021; Revised 25 January 2022; Accepted 26 January 2022; Published 23 February 2022

Academic Editor: Yaming Wang

Copyright (C) 2022 Tatsuaki Miyashita and Hiromu Saito. This is an open access article distributed under the Creative Commons Attribution License, which permits unrestricted use, distribution, and reproduction in any medium, provided the original work is properly cited.

\begin{abstract}
We investigated the effect of the chemical structure of alkylammonium salt on the crystallization behavior of poly(vinylidene fluoride) (PVDF) by DSC, optical microscopy, light scattering, and FT-IR. The nonisothermal and isothermal crystallizations of PVDF were accelerated by adding alkylammonium salt consisting of short alkyl chains and small anion species, and the spherulite size and the ordering in the spherulite became smaller due to the nucleation agent effect. The FT-IR spectra revealed that electroactive $\gamma$-phase was preferentially formed by adding alkylammonium salts though the accelerated crystallization was suppressed due to the steric hindrance effect by the long alkyl chain and large anion species. On the other hand, the formation of the $\gamma$-phase was suppressed when the dispersion of the salt in the PVDF matrix was poor due to the high melting temperature.
\end{abstract}

\section{Introduction}

Poly(vinylidene fluoride) (PVDF) is widely used for industrial applications such as chemical valves, membranes for water treatment, and sensors due to its excellent chemical resistance, weathering resistance, and ferroelectricity $[1,2]$. PVDF forms at least four crystal polymorphs: orthorhombic $\alpha$-, $\beta$ - and $\delta$-phases, and monoclinic $\gamma$-phase [3-6]. The $\alpha$ and $\delta$-phases have a trans-gauche conformation $\left(\mathrm{TGTG}^{\prime}\right)$, the $\beta$-phase has an all-trans planar zigzag conformation (TTT), and the $\gamma$-phase has a sequence of three trans linked to a gauche conformation (TTTGTTTG'). Electrically active $\beta$ - and $\gamma$-phase crystallites are promising for their electric properties such as ferroelectric and piezoelectric ones [2, 4].

The crystalline phase of PVDF depends on processing methods $[3,4,7]$. An electrically inactive $\alpha$-phase is obtained by conventional melt crystallization. On the other hand, electrically active $\beta$-phase is obtained by specific processing, for instance, heat elongation of the $\alpha$-phase crystallites $[8,9]$, plastic deformation [10], electrospray deposition [11], crystallization in polar solvents $[12,13]$, polymer blending
[14], and melt crystallization at ultrahigh cooling speed [15]. The electrically active $\gamma$-phase is generally obtained by melt crystallization at high temperature [16] or annealing at high temperature [17]. It is also known that polar $\beta$ - or $\gamma$-phase can be effectively induced by adding inorganic filler [18] such as nanoclay [19-21], graphene oxide [22], and carbon nanotube [23-27]. The polar phase can also be induced by adding ionic salts [18] such as ionic liquids [28], $\mathrm{KBr}$ [29], cetyltrimethylammonium bromide (CTAB) [30-32], ionic fluorinated surfactant [33], onium salt $[34,35]$. The induction of the polar phase is explained by ion-dipole interactions between ionic salts and PVDF chains. It is revealed that the crystallization rate of PVDF increases significantly by adding the positive nucleation agents, and the nucleation effect is caused by the specific ion-partial dipole interaction. Since the dipole moment of CF2 dipoles is much stronger than that of $\mathrm{CH} 2$ dipoles, the ion-dipole interaction is derived from the interaction between positively charged nucleation agents and CF2 dipoles in PVDF [36]. It is suggested that the surface charge by the nucleation agents is important to control the crystallization behavior of 
PVDF; i.e., the ion-dipole interaction causes the polymer chain to align on the surface of the alkylammonium salt, resulting in the preferential formation of $\beta$ - or $\gamma$-phase $[32,36,37]$. The polar phase is induced in the early stage by ion-dipole interactions in the presence of CTAB [32].

It has been reported that the crystallization rate of the $\gamma$-phase is much slower than that of the $\alpha$-phase $[7,38]$. Well-known nucleation agents such as flavanthrone and poly(tetrafluoroethylene) (PTFE) only accelerate the crystallization of $\alpha$-phase crystallites [39]. On the other hand, ionic salts are able to accelerate the crystallization of $\gamma$-phase crystallites. $\gamma$-phase crystallites were obtained by isothermal crystallization at a high temperature of $165^{\circ} \mathrm{C}$ by adding $\mathrm{KBr}$ powders [29], and the crystallization time of $\gamma$-phase crystallites was drastically shortened by adding ammonium salts $[36,40]$.

It has been widely accepted that the polar phase of PVDF is formed by the ion-dipole interactions between alkylammonium salt and PVDF chains. However, the effect of the chemical structure of alkylammonium salts such as the length of the alkyl chain and the size of anion species, has not been clarified. Most of the crystallization kinetic studies of PVDF in the presence of onium salt were carried out using DSC [40], in which spherulite size is not estimated, though nucleation agents also affect the spherulite size. In this study, we investigated the crystallization kinetics and crystalline structure of PVDF added with a series of alkylammonium salt consisting of various lengths of alkyl chain and various sizes of anion species. The crystallization behavior was discussed by the results of DSC and light scattering measurements for crystallization kinetics, polarized optical microscopic observation for the spherulite structure, and FT-IR for the crystalline phase.

\section{Experimental}

PVDF was supplied by Kureha Corporation, Tokyo, Japan (grade name KF1000). The average molecular weight, determined by gel permeation chromatography (GPC), is $\mathrm{Mw}=240,000$. Figure 1 shows the chemical structures of a series of alkylammonium salts consisting of various alkyl chain lengths and anion species used in this study. The melting temperatures $T_{m} s$ and crystallization temperatures $T_{\mathcal{c}} s$ of these alkylammonium salts are also shown in Figure 1. Alkylammonium salts consisting of different alkyl chain lengths are tetramethylammonium hydrogen sulfate (T1), tetraethylammonium hydrogen sulfate (T2), tetrapropylammonium hydrogen sulfate (T3), tetrabutylammonium hydrogen sulfate (T4), tetrahexylammonium hydrogen sulfate (T5), and hexadecyltrimethylammonium hydrogen sulfate (H16). On the other hand, alkylammonium salts consisting of different anion species are T4, tetrabutylammonium tetrafluoroborate (T4FB), and tetrabutylammonium p-toluene sulfonate (T4TS). T1, T5, H16, T4FB, and T4TS were purchased from Tokyo Chemical Industry Co., Ltd. T3 and T4 were purchased from Sigma-Aldrich and Koei Chemical Company, Limited, respectively.

PVDF powder was added with alkylammonium salts at a weight ratio of 99/1 in a twin blade mixer (Toyo Seiki, R60B,
Japan) attached to a motor and controller (Toyo Seiki, Labo Plastmill 4C150-01, Japan) at $200^{\circ} \mathrm{C}$ and at rotation speed of $60 \mathrm{rpm}$ for $5 \mathrm{~min}$. Film specimens with dimensions of $50 \mathrm{~mm} \times 50 \mathrm{~mm} \times 500 \mu \mathrm{m}$ were prepared by hot pressing at $230^{\circ} \mathrm{C}$, and then quickly cooled by a cold press at $20^{\circ} \mathrm{C}$.

A DSC was carried out at a cooling rate of $10^{\circ} \mathrm{C} / \mathrm{min}$ under a nitrogen atmosphere in a temperature range from $230^{\circ} \mathrm{C}$ to $30^{\circ} \mathrm{C}$ using a DSC 1 manufactured by Mettler Toledo $\mathrm{GmbH}$, Switzerland. For the nonisothermal crystallization, the samples were heated to $230^{\circ} \mathrm{C}$ at a rate of $10^{\circ} \mathrm{C} / \mathrm{min}$ under a nitrogen atmosphere and held at $230^{\circ} \mathrm{C}$ for $5 \mathrm{~min}$ in order to eliminate the previous thermal history. Then, the samples were cooled to $30^{\circ} \mathrm{C}$ at a rate of $10^{\circ} \mathrm{C} / \mathrm{min}$ in order to evaluate the crystallization temperature.

The morphologies of PVDF samples were observed by using a polarized optical microscope (Olympus BX53, Japan) equipped with a CCD camera (Olympus DP74, Japan). The structure under the polarized optical microscope was observed by the optical microscope equipped with a sensitive tint plate, with an optical path difference of $530 \mathrm{~nm}$ under cross polarizers.

The crystalline phase of PVDF was characterized by measuring the infrared spectrum using an ATR-FTIR spectrometer (Horiba FT-730, Japan). All spectra were recorded from 600 to $4000 \mathrm{~cm}^{-1}$ by averaging 25 scans at a resolution of $4 \mathrm{~cm}^{-1}$.

A polarized He-Ne laser with a wavelength of $632.8 \mathrm{~nm}$ was applied vertically to the film specimen. The scattered light was passed through the analyzer and then onto a highly sensitive charge-coupled device (CCD) camera with $800 \times 600$ pixels (Tokyo Instruments pco.1600, Tokyo, Japan). We employed Hv geometries in which the optical axis of the analyzer was vertical to that of the polarizer. The input data from the CCD camera were stored on a personal computer for further analysis. The test area irradiated by the laser was about $\pi(10$ [3]) $\mu \mathrm{m}$ [2] and the area of a spherulite was about $\pi$ (10) $\mu \mathrm{m}$ [2]. Hence, the relative size of the test area and the spherulite is about $10^{4}$ when the diameter of the spherulite is $10 \mu \mathrm{m}$.

\section{Results and Discussion}

3.1. Nonisothermal Crystallization. Figure 2 shows the DSC thermograms recorded during the cooling process at a rate of $10^{\circ} \mathrm{C} / \mathrm{min}$ from the molten state at $230^{\circ} \mathrm{C}$ for neat PVDF and the PVDF added with $1 \mathrm{wt} \%$ of various alkylammonium salts consisting of different lengths of alkyl chain and different sizes of anion species. The list of onset, peak, and offset temperatures of crystallization obtained from Figure 2 is shown in Table 1. The DSC thermogram of the neat PVDF showed an exothermic peak at around $140^{\circ} \mathrm{C}$ due to the crystallization; i.e., the crystallization started at $143^{\circ} \mathrm{C}$ and ended at $136^{\circ} \mathrm{C}$ during the cooling process. The onset temperature of the crystallization was found to shift to a higher temperature by adding tetraalkylammonium salts such as $\mathrm{T} 1-\mathrm{T} 5$, e.g., the shift was about $6^{\circ} \mathrm{C}$ for PVDF by adding $\mathrm{T} 1, \mathrm{~T} 2$, and $\mathrm{T} 4$, while it was about $4^{\circ} \mathrm{C}$ by adding $\mathrm{T} 3$ and T5 (Figure 2(a) and Table 1). The results suggest that crystallization of PVDF is accelerated by adding 


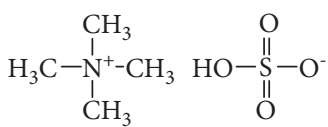

$\mathrm{T} 1$

Tetramethylammonium hydrogen sulfate $\mathrm{Tm}>260^{\circ} \mathrm{C}, \mathrm{Tc}: \mathrm{ND}$<smiles>CCC[N+](CCC)(CCC)CCC</smiles>

T3

Tetrapropylammonium hydrogen sulfate $\mathrm{Tm}: 161^{\circ} \mathrm{C}, \mathrm{Tc}: 79^{\circ} \mathrm{C}$

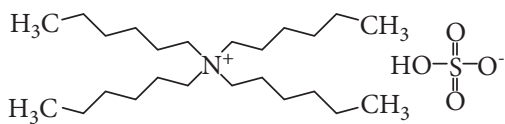

T5

Tetrahexylammonium hydrogen sulfate $\mathrm{Tm}: 104^{\circ} \mathrm{C}, \mathrm{Tc}: \mathrm{ND}$

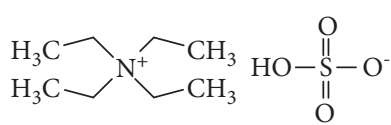

$\mathrm{T} 2$

Tetraethylammonium hydrogen sulfate $\mathrm{Tm}: 240^{\circ} \mathrm{C}, \mathrm{Tc}: 230^{\circ} \mathrm{C}$<smiles>CCCC[N+](CCCC)(CCCC)CCCC</smiles>

$\mathrm{T} 4$

Tetrabutylammonium hydrogen sulfate $\mathrm{Tm}: 174^{\circ} \mathrm{C}, \mathrm{Tc}: 135^{\circ} \mathrm{C}$<smiles>CCCCCCCCCCCCCCCC[N+](C)(C)C</smiles>

H16

Hexadecyltrimethylammonium hydrogen sulfate Tm: $75^{\circ} \mathrm{C}, \mathrm{Tc}: \mathrm{ND}$

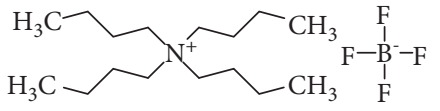

T4FB

Tetrabutylammonium tetrafluoroborate $\mathrm{Tm}: 162^{\circ} \mathrm{C}, \mathrm{Tc}: 134^{\circ} \mathrm{C}$<smiles>CCCC[N+](CCCC)(CCCC)CCCC</smiles>

T4TS

Tetrabutylammonium p-toluene sulfonate $\mathrm{Tm}: 45^{\circ} \mathrm{C}$, Tc:ND

Figure 1: Chemical structures Tm and Tc of a series of alkylammonium salts with various lengths of alkyl chain and various sizes of anion species added in PVDF.

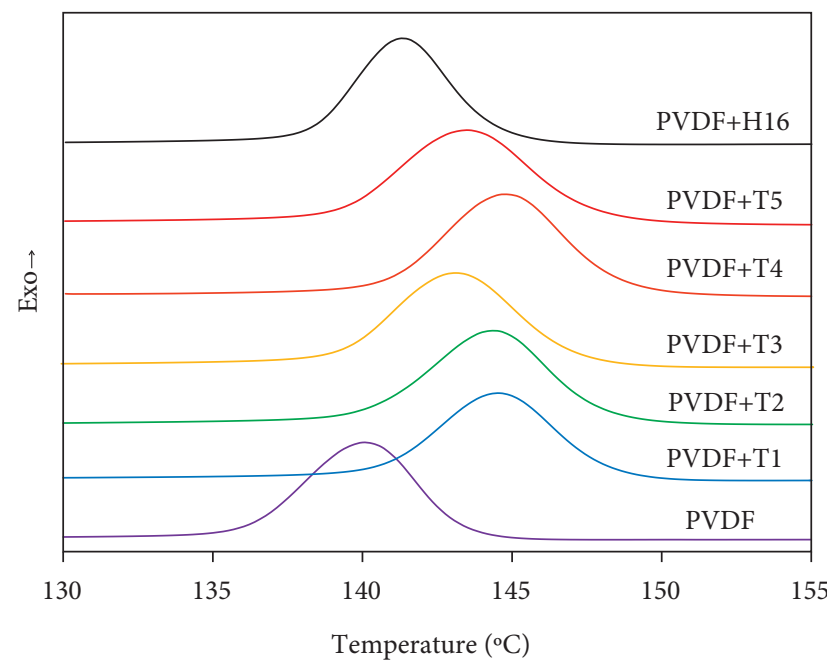

(a)

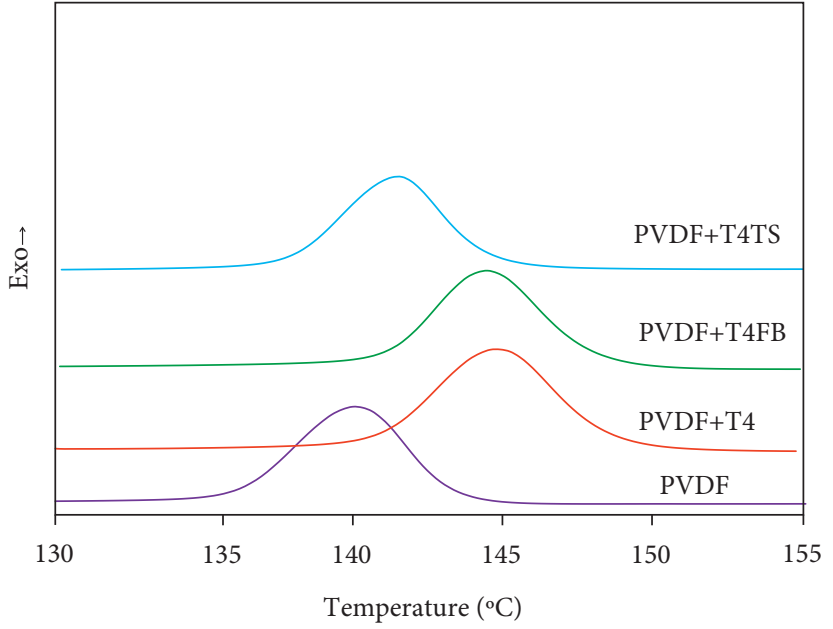

(b)

FIGURE 2: DSC thermograms during the nonisothermal crystallization of neat PVDF and PVDF added with various alkylammonium salts at cooling rate of $10^{\circ} \mathrm{C} / \mathrm{min}$ : (a) PVDF added with T1, T2, T3, T4, T5, and H16 and (b) PVDF added with T4, T4FB, and T4TS.

tetraalkylammonium salt with a short alkyl chain. On the other hand, the PVDF added with hexadecyltrimethylammonium salt H16 exhibited a small shift, suggesting that the acceleration is small by adding alkylammonium salt with a long alkyl chain. T1-T5 showed similar nucleation effects even though the melting 
TABLE 1: DSC Parameters of nonisothermal crystallization for neat PVDF and PVDF with alkylammonium salts.

\begin{tabular}{lccc}
\hline & \multicolumn{3}{c}{ Nonisothermal crystallization } \\
& Onset $\left({ }^{\circ} \mathrm{C}\right)$ & Peak $\left({ }^{\circ} \mathrm{C}\right)$ & Offset $\left({ }^{\circ} \mathrm{C}\right)$ \\
\hline PVDF & 143 & 140 & 136 \\
PVDF + T1 & 148 & 144 & 141 \\
PVDF + T2 & 148 & 144 & 140 \\
PVDF + T3 & 147 & 143 & 139 \\
PVDF + T4 & 149 & 145 & 141 \\
PVDF + T5 & 147 & 143 & 139 \\
PVDF + H16 & 145 & 141 & 138 \\
PVDF + T4FB & 148 & 144 & 141 \\
PVDF + T4TS & 145 & 141 & 138 \\
\hline
\end{tabular}

temperature $T_{m}$ and crystallization temperature $T_{c}$ of the alkylammonium salt were different as shown in Figure 1, e.g., the melting temperatures of $\mathrm{T} 2, \mathrm{~T} 4$ and $\mathrm{T} 5$ were $240^{\circ} \mathrm{C}$, $174^{\circ} \mathrm{C}$, and $104^{\circ} \mathrm{C}$, respectively. Thus, the physical properties of alkylammonium salts such as melting temperatures and crystallization temperatures are not important on the accelerated crystallization, but the ion-dipole interaction of alkylammonium salts and PVDF is important to accelerate the crystallization of PVDF [32, 36, 37]. The alkylammonium salts consisting of short alkyl chains such as T1-T5 exhibit large accelerated crystallization due to the ion-dipole interaction of salts and PVDF chains, while H16, having a long alkyl chain, exhibits small accelerated crystallization due to the steric hindrance derived from the long alkyl chain which weakens the ion-dipole interaction of the alkylammonium salt and PVDF.

The onset crystallization temperature and the exothermic peaks of PVDF were shifted to a higher temperature of about $5^{\circ} \mathrm{C}$ by adding tetrabutylammonium salts such as T4 and T4FB having small size of anion species, while the acceleration was small by adding T4TS having p-toluene sulfonate in which the size of the anion species is larger than those of T4 and T4FB (Figure 2(b) and Table 1). The result suggests that steric hindrance by large anion species weakens the ion-dipole interaction of alkylammonium salt and PVDF and the accelerated crystallization is suppressed, as suggested in the steric hindrance in the alkylammonium salts consisting of long alkyl chains shown in Figure 2(a).

3.2. Isothermal Crystallization. To confirm the accelerated crystallization of PVDF by alkylammonium salts, isothermal crystallization behavior was investigated by light scattering measurement. The crystallization kinetics can be estimated by the integrated light scattering intensity in $\mathrm{Hv}$ mode, i.e., the invariant $Q_{H \nu}$ defined as follows [41-43]:

$$
Q_{H v}=\int_{0}^{\infty} I(q) q^{2} \mathrm{~d} q,
$$

where $q$ is the scattering vector, $q=(4 \pi / \lambda) \sin (\theta / 2), \lambda$ and $\theta$ are the wavelength and the scattering angle, respectively, and $I(q)$ is the intensity of the scattered light of the $H v$ mode at $q$. The invariant in $H v$ mode $Q_{H V}$ is described by the mean square optical anisotropy $<\delta>[2]$ as follows:

$$
Q_{H v} \propto\left\langle\delta^{2}\right\rangle=\phi_{s}\left(\alpha_{r}-\alpha_{t}\right)^{2},
$$

where $\phi_{s}$ is the volume fraction of the spherulite, and $\alpha_{r}$ and $\alpha_{t}$ are the radial and tangential polarizabilities of the spherulite, respectively [42]. Since $\left(\alpha_{r}-\alpha_{t}\right)$ in equation (2) is ascribed to the intrinsic anisotropy of the crystalline region and the orientation function for the optical axis of the crystalline region, the ordering in the spherulite can be provided quantitatively by the light scattering intensity in addition to the volume fraction of the spherulite.

Figure 3 shows time evolutions of the invariant $Q_{H v}$ during isothermal crystallization at $155^{\circ} \mathrm{C}$ after a temperature drop from $230^{\circ} \mathrm{C}$ for neat PVDF and PVDF added with various alkylammonium salts consisting of different lengths of alkyl chain and different sizes of anion species. The $Q_{H v}$ increased with time by associating with the spherulite growth and leveled off when spherulites filled the whole space as expected from the $\phi_{s}$ in equation (2). The crystallization of neat PVDF started to occur at around $3 \mathrm{~min}$ and ended at around $15 \mathrm{~min}$. The end time of crystallization was found to shifted to a shorter time by adding alkylammonium hydrogen sulfate of $\mathrm{T} 1$ - T5, i.e., the end time was shifted to $4-5 \mathrm{~min}$ by adding $\mathrm{T} 1-\mathrm{T} 5$, while it was shifted to about $7 \mathrm{~min}$ by adding H16 (Figure 3(a)). These results indicate that T1-T5 showed accelerated crystallization of PVDF; i.e., alkylammonium salts consisting of short alkyl chains from methyl to hexyl accelerated the crystallization of PVDF. On the other hands, the alkylammonium salt of $\mathrm{H} 16$ consisting of a long hexadecyl chain showed a small acceleration due to the steric hindrance effect by the long alkyl chain. These results support the accelerated crystallization by alkylammonium salts consisting of short alkyl chains suggested by the nonisothermal crystallization behavior shown in Figure 2(a).

The end time of crystallization of PVDF was shifted to shorter time of $5 \mathrm{~min}$ by adding T4 and T4FB, while the shift was small in the PVDF by adding T4TS (Figure 3(b)). Hence, tetrabutylammonium salt consisting of small anion species such as hydrogen sulfate and tetrafluoroborate shows large acceleration due to the ion-dipole interaction of salts and PVDF chains, while T4TS consisting of large anion species shows small acceleration due to steric hindrance by the large anion species which weakens the iondipole interaction of alkylammonium salt and PVDF. These results support the accelerated crystallization by alkylammonium salts consisting of small anion species as suggested by the nonisothermal crystallization behavior shown in Figure 2(b).

As shown in Figure 3, the $Q_{H v}$ of the PVDF became smaller by adding alkylammonium salt. Since the volume fraction of the spherulite $\phi_{s}$ in equation (2) was 1 when the crystallization was ended, the difference of the $Q_{H v}$ is attributed to the polarizability difference in the spherulite $\alpha_{r}-\alpha_{t}$. Since $\left(\alpha_{r}-\alpha_{t}\right)$ is ascribed to the intrinsic anisotropy of the crystalline region and the orientation function for the optical axis of the crystalline region, the small value of $Q_{H v}$ is attributed to the low orientation of the optical axis along the radial direction in the spherulite. Thus, the 

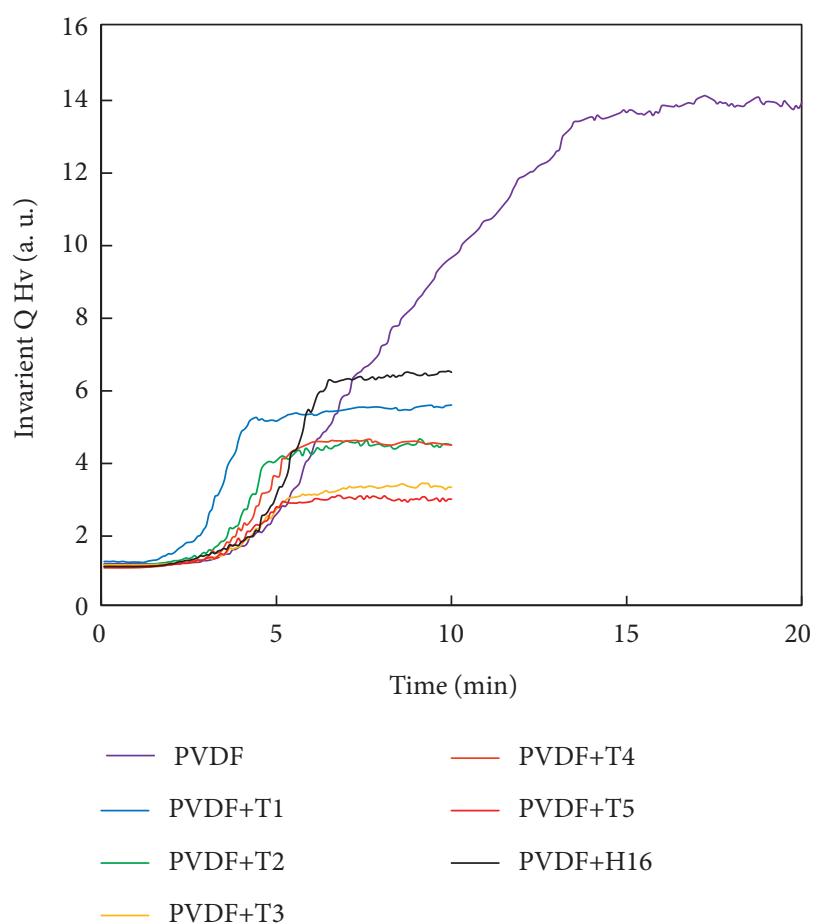

(a)

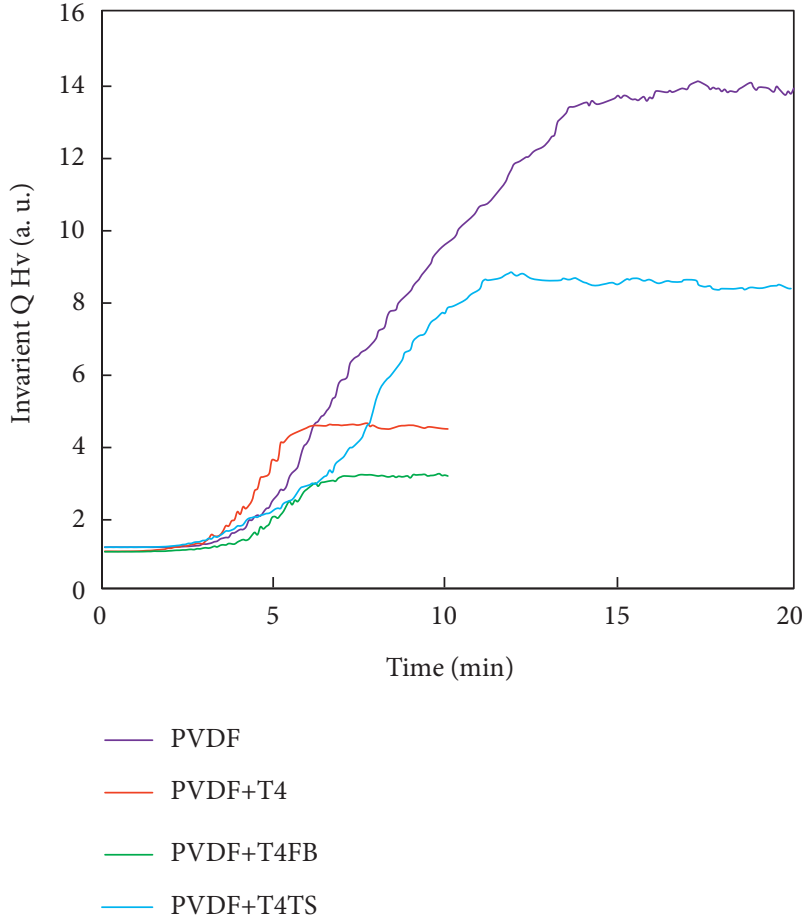

(b)

FIgURE 3: Time evolutions of the invariant $\mathrm{Q}_{\mathrm{Hv}}$ for neat PVDF and PVDF added with various alkylammonium salts during isothermal crystallization at $155^{\circ} \mathrm{C}$ : (a) PVDF added with T1, T2, T3, T4, T5, and H16 and (b) PVDF added with T4, T4FB, and T4TS.

result suggests that the order of the crystallites in the spherulite of PVDF becomes smaller by adding alkylammonium salt.

Figure 4 shows the polarized optical micrographs of neat PVDF and PVDF added with various alkylammonium salts obtained by isothermal crystallization at $155^{\circ} \mathrm{C}$. The spherulites of the PVDF added with alkylammonium salt except for H16 and T4TS were definitely smaller than those of the neat PVDF. The decrease of the spherulite size by adding alkylammonium salts is attributed to the increase of the crystal nuclei. Thus, the accelerated crystallization shown in Figure 3 is caused by the nucleation agent effect of the alkylammonium salts due to the ion-dipole interaction of the alkylammonium salts and PVDF. It is considered that ion-dipole interaction between the positive surface of nucleation agents and the partially negative CF2 dipoles of PVDF causes a decrease in the free energy barrier for nucleation [32, 36, 37]. In the PVDF added with T1, aggregates of $\mathrm{T} 1$ were observed due to poor dispersion of T1 in the PVDF matrix owing to the high melting temperature, i.e., the melting temperature of $\mathrm{T} 1$ was above $260^{\circ} \mathrm{C}$. In spite of the poor dispersion, the spherulite was smaller than that of neat PVDF, indicating the nucleation agent effect of the T1. The PVDF added with T16 and T4TS showed vivid interference color similar to that of the neat PVDF, while the interference color was light in the PVDF added with those of other salts in which the $Q_{H v}$ in Figure 3 was small. These results suggest that crystallization of PVDF is accelerated due to the nucleation agent effect, and the ordering of the crystallites in the spherulite becomes smaller by adding alkylammonium salt consisting of short chains and small sizes of anion species, as suggested by the light scattering measurements shown in Figure 3.

3.3. Crystalline Structure. Figure 5 shows the representative FT-IR spectra of the neat PVDF and the PVDF added with various alkylammonium salts obtained by isothermal crystallization at $155^{\circ} \mathrm{C}$. The characteristic bands of the $\alpha$-phase were observed at 766,795 , and $976 \mathrm{~cm}^{-1}$ in the neat PVDF, indicating that $\alpha$-phase crystallites are obtained during the isothermal crystallization in the neat PVDF. On the other hand, the characteristic band of the $\gamma$-phase was observed at $1234 \mathrm{~cm}^{-1}$ in the PVDF added with T1, T4, H16, T4FB, and T4TS, indicating that $\gamma$-phase is induced by adding alkylammonium salt during the isothermal crystallization at $155^{\circ} \mathrm{C}$. A small peak was seen at $766 \mathrm{~cm}^{-1}$ in the PVDF added with T1, while no characteristic peak of the $\alpha$-phase was seen in the PVDF added with T4, H16, T4FB, and T4TS, indicating that $\alpha$-phase remains by adding T1, while $\alpha$-phase does not remain by adding T4, H16, T4FB, and T4TS.

The fraction of the $\gamma$-phase $\phi(\gamma)$ is given as follows $[4,44]$ :

$$
\phi(\gamma)=\frac{A_{\gamma}}{\left(K_{\gamma} / K_{\alpha}\right) A_{\alpha}+A_{\gamma}},
$$

where $A_{j}$ is the baseline-corrected absorbance at $j \mathrm{~cm}^{-1}$, and $K_{\alpha}$ and $K_{\gamma}$ are the absorption coefficients at the respective wavenumbers, i.e., $K_{\alpha}$ and $K_{\gamma}$ are 0.365 and $0.150 \mathrm{~cm}^{-1}$, 


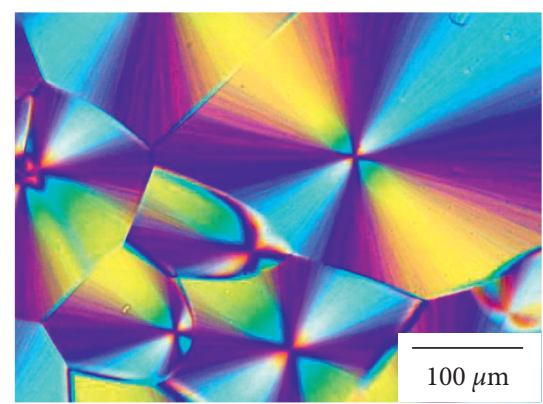

PVDF

(a)

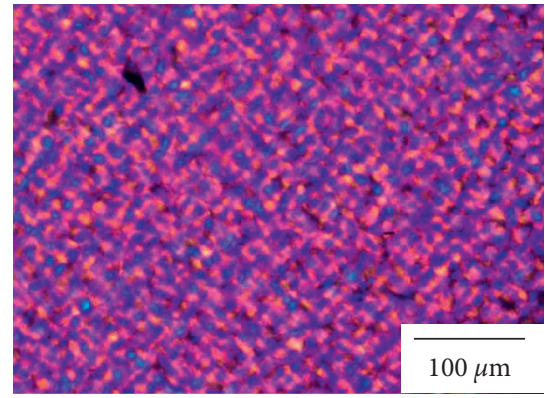

PVDF+T3

(d)

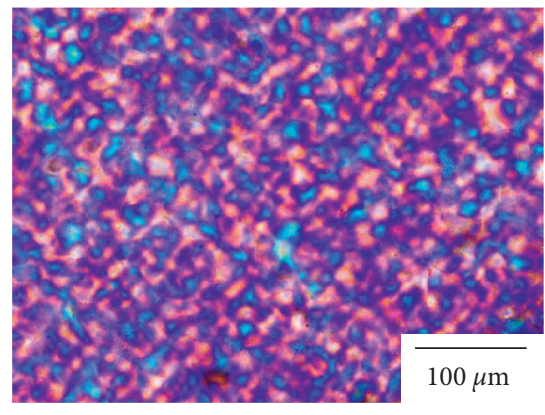

PVDF+H16

(g)

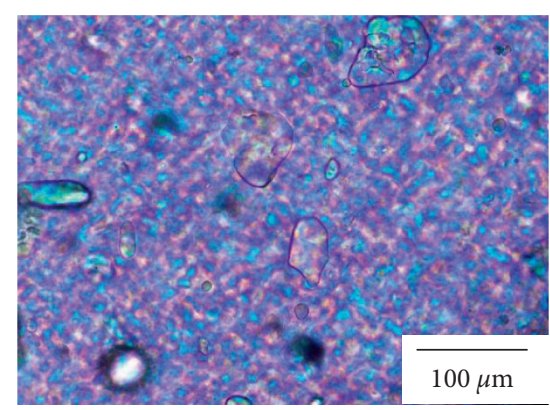

PVDF+T1

(b)

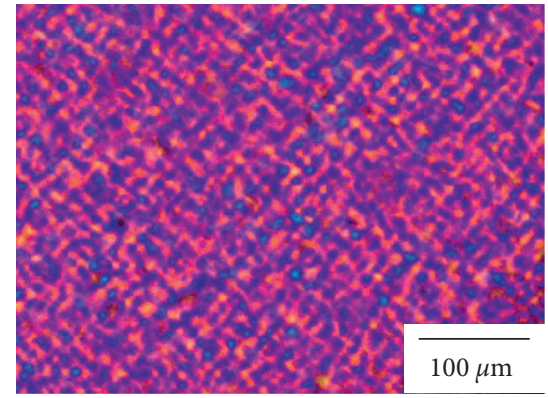

PVDF+T4

(e)

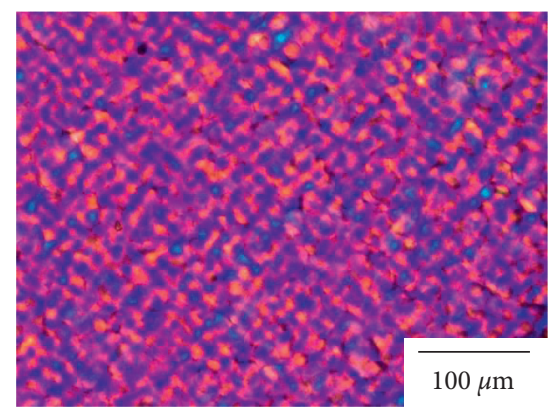

PVDF+T4FB

(h)

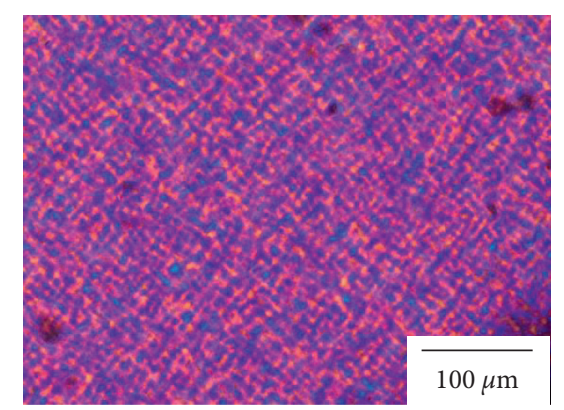

PVDF+T2

(c)

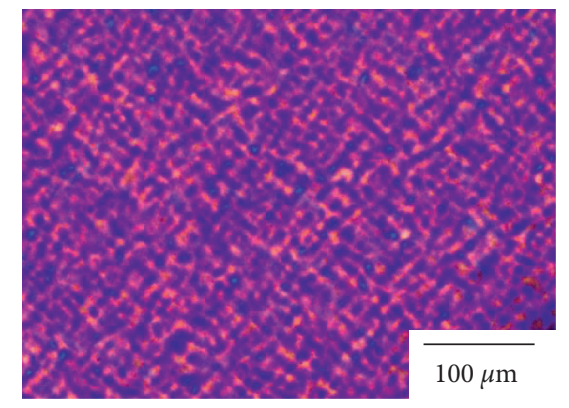

PVDF+T5

(f)

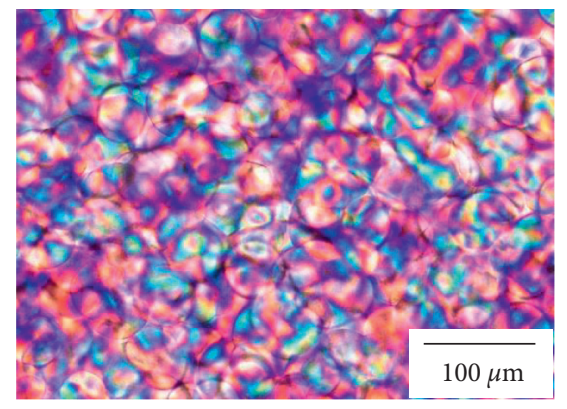

PVDF+T4TS

(i)

FIGURe 4: Polarized optical micrographs of neat PVDF and PVDF added with various alkylammonium salts obtained by isothermal crystallization at $155^{\circ} \mathrm{C}$. (a) PVDF. (b) PVDF + T1. (c) PVDF + T2. (d) PVDF + T3. (e) PVDF + T4. (f) PVDF + T5. (g) PVDF + H16. (h) PVDF + T4FB. (i) PVDF + T4TS.

respectively. Table 2 shows the fraction of $\alpha$ - and $\gamma$-phase in the neat PVDF and the PVDF added with alkylammonium salt obtained from Figure 5 and equation (3). The $\gamma$-phase was obtained in the PVDF by adding the alkylammonium salt, indicating that alkylammonium salt acts as a nucleation agent for the $\gamma$-phase. The ion-dipole interaction causes the polymer chain to align on the surface of the alkylammonium salt, resulting in the preferential formation of $\beta$ - or $\gamma$-phase $[32,36,37]$. The interesting result here is that the $\gamma$-phase was also induced by adding alkylammonium salts consisting of long chains and large sizes of anion specie such as H16 and T4TS though the nucleation agent effect was small. On the other hand, the $\alpha$-phase remained by adding the alkylammonium salt of $\mathrm{Tl}$ due to the poor dispersion owing to the high melting temperature of T1, though the nucleation agent effect for the accelerated crystallization was large. The fast crystallization rate by adding $\mathrm{T} 1 \mathrm{might}$ be attributed to the crystallization of the $\alpha$-phase, because the crystallization of the $\alpha$-phase is faster than that of the $\gamma$-phase. Thus, good dispersion of the alkylammonium salt is required for the formation of the $\gamma$-phase while the short chain of the alkylammonium salt and the small size of the anion species are required for the nucleation agent effect on the accelerated crystallization. 


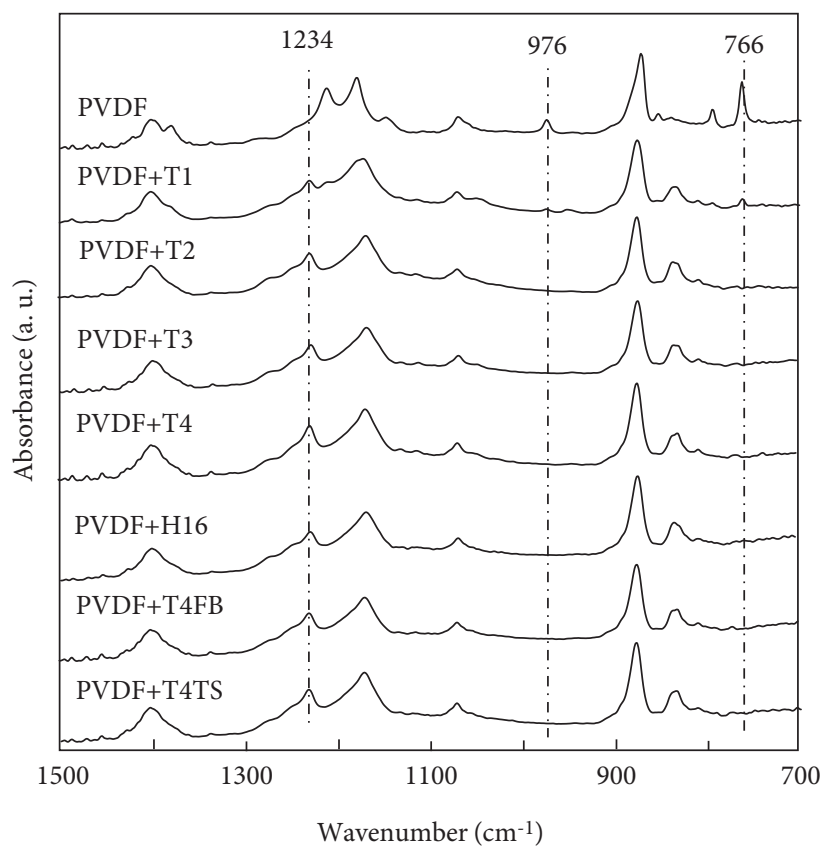

FIgURE 5: FT-IR spectra for crystalline phase of neat PVDF and PVDF added with various alkylammonium salts obtained by isothermal crystallization at $155^{\circ} \mathrm{C}$.

TABLE 2: The fraction of crystalline phase of neat PVDF and PVDF added with various alkylammonium salts obtained by isothermal crystallization at $155^{\circ} \mathrm{C}$ and nonisothermal crystallization at a rate of $10^{\circ} \mathrm{C} / \mathrm{min}$.

\begin{tabular}{lcccc}
\hline & \multicolumn{2}{c}{ Isothermal crystallization } & \multicolumn{2}{c}{ Nonisothermal crystallization } \\
& $\alpha(\%)$ & $\gamma(\%)$ & $\alpha(\%)$ & 100 \\
PVDF & 100 & 0 & 7 & 0 \\
PVDF + T1 & 17 & 83 & 0 & 93 \\
PVDF + T2 & 0 & 100 & 0 & 100 \\
PVDF + T3 & 0 & 100 & 0 & 100 \\
PVDF + T4 & 0 & 100 & 0 & 100 \\
PVDF + H16 & 0 & 100 & 0 & 100 \\
PVDF + T4FB & 0 & 100 & 0 & 100 \\
PVDF + T4TS & 0 & 100 & 100 \\
\hline
\end{tabular}

\section{Conclusion}

The crystallization of PVDF was accelerated in the nonisothermal and isothermal procedures by adding an alkylammonium salt consisting of short chains and small sizes of anion species due to the nucleation agent effect, and the size of the spherulite and the ordering of the crystallites in the spherulite became smaller. The alkylammonium salts also acted as nucleation agents for the electroactive $\gamma$-phase. The short chain of the alkylammonium salt and the small size of the anion species are required for the nucleation agent effect on the accelerated crystallization of PVDF to cause a decrease in the free energy barrier for nucleation by ion-dipole interaction between the positive surface of the alkylammonium salt and the partially negative CF2 dipoles of PVDF. On the other hand, good dispersion of the alkylammonium salt in the PVDF matrix is required for the formation of the $\gamma$-phase to align on the surface of the alkylammonium salt by the ion-dipole interaction.

\section{Data Availability}

No data were used to support this study.

\section{Conflicts of Interest}

The authors declare that they have no conflicts of interest.

\section{References}

[1] Z. Cui, N. T. Hassankiadeh, Y. Zhuang, E. Drioli, and Y. M. Lee, "Crystalline polymorphism in poly(vinylidenefluoride) membranes," Progress in Polymer Science, vol. 51, pp. 94-126, 2015.

[2] L. Ruan, X. Yao, Y. Chang, L. Zhou, G. Qin, and X. Zhang, "Properties and applications of the beta phase poly(vinylidene fluoride)," Polymers, vol. 10, no. 3, 2018.

[3] B. Ameduri, "From vinylidene fluoride (VDF) to the applications of VDF-containing polymers and copolymers: recent developments and future trends," Chemical Reviews, vol. 109, no. 12, pp. 6632-6686, 2009. 
[4] P. Martins, A. C. Lopes, and S. Lanceros-Mendez, "Electroactive phases of poly(vinylidene fluoride): determination, processing and applications," Progress in Polymer Science, vol. 39, no. 4, pp. 683-706, 2014.

[5] A. J. Lovinger, "Annealing of poly(vinylidene fluoride) and formation of a fifth phase," Macromolecules, vol. 15, no. 1, pp. 40-44, 1982.

[6] R. Gregorio and D. S. Borges, "Effect of crystallization rate on the formation of the polymorphs of solution cast poly(vinylidene fluoride)," Polymer, vol. 49, no. 18, pp. 4009-4016, 2008.

[7] D. C. Bassett, Developments in Crystalline Polymers, Vol. 1, Springer, , Berlin, Germany, 1982.

[8] A. Salimi and A. A. Yousefi, "Analysis method," Polymer Testing, vol. 22, no. 6, pp. 699-704, 2003.

[9] H. Guo, Y. Zhang, F. Xue et al., "In-situ synchrotron SAXS and WAXS investigations on deformation and $\alpha-\beta$ transformation of uniaxial stretched poly(vinylidene fluoride)," CrystEngComm, vol. 15, no. 8, 2013.

[10] G. A. Maier, G. Wallner, R. W. Lang, and P. Fratzl, "Structural changes during plastic deformation at crack tips in PVDF films: a scanning X-ray scattering study," Macromolecules, vol. 38, no. 14, pp. 6099-6105, 2005.

[11] T. Danno, H. Matsumoto, M. Nasir et al., "Fine structure of PVDF nanofiber fabricated by electrospray deposition," Journal of Polymer Science Part B: Polymer Physics, vol. 46, no. 6, pp. 558-563, 2008.

[12] A. Salimi and A. A. Yousefi, "Conformational changes and phase transformation mechanisms in PVDF solution-cast films," Journal of Polymer Science Part B: Polymer Physics, vol. 42, no. 18, pp. 3487-3495, 2004.

[13] H. Horibe, Y. Sasaki, H. Oshiro et al., "Quantification of the solvent evaporation rate during the production of three PVDF crystalline structure types by solvent casting," Polymer Journal, vol. 46, no. 2, pp. 104-110, 2013.

[14] H. Horibe, Y. Hosokawa, H. Oshiro et al., "Effect of heattreatment temperature after polymer melt and blending ratio on the crystalline structure of PVDF in a PVDF/PMMA blend," Polymer Journal, vol. 45, no. 12, pp. 1195-1201, 2013.

[15] A. Gradys, P. Sajkiewicz, S. Adamovsky, A. Minakov, and C. Schick, "Crystallization of poly(vinylidene fluoride) during ultra-fast cooling," Thermochimica Acta, vol. 461, no. 1-2, pp. 153-157, 2007.

[16] S. Osaki and Y. Ishida, "Effects of annealing and isothermal crystallization upon crystalline forms of poly(vinylidene fluoride)," Journal of Polymer Science Polymer Physics Edition, vol. 13, no. 6, pp. 1071-1083, 1975.

[17] W. M. Prest Jr. and D. J. Luca, "The formation of the $\gamma$ phase from the $\alpha$ and $\beta$ polymorphs of polyvinylidene fluoride," Journal of Applied Physics, vol. 49, no. 10, pp. 5042-5047, 1978.

[18] Prateek, V. K. Thakur, and R. K. Gupta, "Recent progress on ferroelectric polymer-based nanocomposites for high energy density capacitors: synthesis, dielectric properties, and future aspects," Chemical Reviews, vol. 116, no. 7, pp. 4260-4317, 2016.

[19] L. Priya and J. P. Jog, "Polymorphism in intercalated poly(vinylidene fluoride)/clay nanocomposites," Journal of Applied Polymer Science, vol. 89, no. 8, pp. 2036-2040, 2003.

[20] J. Yang, J. Wang, Q. Zhang et al., "Cooperative effect of shear and nanoclay on the formation of polar phase in poly(vinylidene fluoride) and the resultant properties," Polymer, vol. 52, no. 21, pp. 4970-4978, 2011.

[21] R. Neppalli, S. Wanjale, M. Birajdar, and V. Causin, "The effect of clay and of electrospinning on the polymorphism, structure and morphology of poly(vinylidene fluoride)," European Polymer Journal, vol. 49, no. 1, pp. 90-99, 2013.

[22] Y. Li, J.-Z. Xu, L. Zhu, G.-J. Zhong, and Z.-M. Li, "Role of iondipole interactions in nucleation of gamma poly(vinylidene fluoride) in the presence of graphene oxide during melt crystallization," The Journal of Physical Chemistry B, vol. 116, no. 51, pp. 14951-14960, 2012.

[23] A. Lund, C. Gustafsson, H. Bertilsson, and R. W. Rychwalski, "Enhancement of $\beta$ phase crystals formation with the use of nanofillers in PVDF films and fibres," Composites Science and Technology, vol. 71, no. 2, pp. 222-229, 2011.

[24] Y. Ahn, J. Y. Lim, S. M. Hong et al., "Enhanced piezoelectric properties of electrospun poly(vinylidene fluoride)/multiwalled carbon nanotube composites due to high $\beta$-phase formation in poly(vinylidene fluoride)," Journal of Physical Chemistry C, vol. 117, no. 22, pp. 11791-11799, 2013.

[25] A. Mandal and A. K. Nandi, "Ionic liquid integrated multiwalled carbon nanotube in a poly(vinylidene fluoride) matrix: formation of a piezoelectric $\beta$-polymorph with significant reinforcement and conductivity improvement," ACS Applied Materials \& Interfaces, vol. 5, no. 3, pp. 747-760, 2013.

[26] K. Ke, P. Pötschke, D. Jehnichen, D. Fischer, and B. Voit, "Achieving $\beta$-phase poly(vinylidene fluoride) from melt cooling: effect of surface functionalized carbon nanotubes," Polymer, vol. 55, no. 2, pp. 611-619, 2014.

[27] S. Barrau, A. Ferri, A. Da Costa et al., "Nanoscale investigations of $\alpha$ - and $\gamma$-crystal phases in PVDF-based nanocomposites," ACS Applied Materials \& Interfaces, vol. 10, no. 15, pp. 13092-13099, 2018.

[28] C. Xing, J. Guan, Y. Li, and J. Li, "Effect of a room-temperature ionic liquid on the structure and properties of electrospun poly(vinylidene fluoride) nanofibers," ACS Applied Materials \& Interfaces, vol. 6, no. 6, pp. 4447-4457, 2014.

[29] T. Miyazaki, Y. Takeda, M. Akasaka, M. Sakai, and A. Hoshiko, "Preparation of isothermally crystallized $\gamma$-form poly(vinylidene fluoride) films by adding a $\mathrm{KBr}$ powder as a nucleating agent," Macromolecules, vol. 41, no. 7, pp. 2749-2753, 2008.

[30] J.-Y. Ren, G. Zhang, Y. Li et al., "Effect of ion-dipole interaction on the formation of polar extended-chain crystals in high pressure-crystallized poly(vinylidene fluoride)," Polymer, vol. 158, pp. 204-212, 2018.

[31] C.-L. Liang, Q. Xie, R.-Y. Bao, W. Yang, B.-H. Xie, and M.-B. Yang, "Induced formation of polar phases in poly(vinylidene fluoride) by cetyl trimethyl ammonium bromide," Journal of Materials Science, vol. 49, no. 12, pp. 4171-4179, 2014.

[32] Y. Li, J.-Z. Xu, L. Zhu et al., "Multiple stage crystallization of gamma phase poly(vinylidene fluoride) induced by ion-dipole interaction as revealed by time-resolved FTIR and two-dimensional correlation analysis," Polymer, vol. 55, no. 18, pp. 4765-4775, 2014.

[33] M. Nasir, H. Matsumoto, M. Minagawa, A. Tanioka, T. Danno, and H. Horibe, "formation of $\beta$-phase crystalline structure of PVDF nanofiber by electrospray deposition: additive effect of ionic fluorinated surfactant," Polymer Journal, vol. 39, no. 7, pp. 670-674, 2007.

[34] R. P. Vijayakumar, D. V. Khakhar, and A. Misra, "Phase transformation and enhancement of toughness in polyvinylidene fluoride by onium salts," Journal of Polymer Science Part B: Polymer Physics, vol. 49, no. 18, pp. 1339-1344, 2011.

[35] J. Wang, Q. Fu, and Q. Zhang, "Inducing of dominant polar forms in poly(vinylidene fluoride) with super toughness by adding alkyl ammonium salt," Polymer, vol. 53, no. 24, pp. 5455-5458, 2012. 
[36] Y. Wu, S. L. Hsu, C. Honeker, D. J. Bravet, and D. S. Williams, "The role of surface charge of nucleation agents on the crystallization behavior of poly(vinylidene fluoride)," The Journal of Physical Chemistry B, vol. 116, no. 24, pp. 73797388, 2012.

[37] C.-L. Liang, Z.-H. Mai, Q. Xie et al., "Induced formation of dominating polar phases of poly(vinylidene fluoride): positive ion- $\mathrm{CF} 2$ dipole or negative ion- $\mathrm{CH} 2$ dipole interaction," The Journal of Physical Chemistry B, vol. 118, no. 30, pp. 91049111, 2014.

[38] M. P. Silva, V. Sencadas, G. Botelho et al., " $\alpha$ - and $\gamma$-PVDF: crystallization kinetics, microstructural variations and thermal behaviour," Materials Chemistry and Physics, vol. 122, no. 1, pp. 87-92, 2010.

[39] S. Schneider, X. Drujon, B. Lotz, and J. C. Wittmann, "Selfnucleation and enhanced nucleation of polyvinylidene fluoride ( $\alpha$-phase)," Polymer, vol. 42, no. 21, pp. 8787-8798, 2001.

[40] C.-L. Liang, Z.-H. Mai, Q. Xie et al., "Crystallization kinetics of $\gamma$ phase poly (vinylidene fluoride)(PVDF) induecd by tetrabutylammonium bisulfate," Journal of Polymer Research, vol. 21, no. 12, pp. 1-8, 2014.

[41] H. Tomura, H. Saito, and T. Inoue, "Light scattering analysis of upper critical solution temperature behavior in a poly(vinylidene fluoride)/poly(methyl methacrylate) blend," Macromolecules, vol. 25, no. 5, pp. 1611-1614, 1992.

[42] J. Koberstein, T. P. Russell, and R. S. Stein, "Total integrated light-scattering intensity from polymeric solids," Journal of Polymer Science Polymer Physics Edition, vol. 17, no. 10, pp. 1719-1730, 1979.

[43] C. H. Lee, H. Saito, and T. Inoue, "Time-resolved light scattering studies on the early stage of crystallization in poly(ethylene terephthalate)," Macromolecules, vol. 26, no. 24, pp. 6566-6569, 1993.

[44] X. Cai, T. Lei, D. Sun, and L. Lin, "A critical analysis of the $\alpha, \beta$ and $\gamma$ phases in poly(vinylidene fluoride) using FTIR," RSC Advances, vol. 7, no. 25, pp. 15382-15389, 2017. 